Article

\title{
Enzymatic Synthesis of Estolides from Castor Oil
}

\author{
Amine Arslan, Anders Rancke-Madsen and Jesper Brask * \\ Novozymes A/S, Biologiens Vej 2, 2800 Kgs. Lyngby, Denmark; aminekarslan@gmail.com (A.A.); \\ arm@novozymes.com (A.R.-M.) \\ * Correspondence: jebk@novozymes.com
}

Received: 22 June 2020; Accepted: 14 July 2020; Published: 24 July 2020

\begin{abstract}
Estolides are fatty acid polyesters with applications in both industry and consumer products. Recently, reports have emerged detailing lipase-catalyzed synthesis of estolides from free hydroxy fatty acids. In this paper, we describe a simple alternative enzymatic process, in which castor oil is directly converted to an estolide mixture by Candida antarctica lipase A (CALA) catalyzed transesterification. The reaction mixture is analyzed by NMR to determine the estolide number (EN) and MALDI MS to identify individual components, in addition to titration to determine the acid value $(\mathrm{AV})$. Estolide trimers and tetramers (EN 2-3) were formed over $24 \mathrm{~h}$ in a system with 2:1 (v/v) castor oil-water. Further, utilizing different lipase specificities, addition of Thermomyces lanuginosus lipase (TLL), allowed the CALA product mixture to be cleaned up by hydrolyzing attached glycerol. In addition, a three-enzyme process is suggested, in which a simple alcohol is added and Candida antarctica lipase B (CALB) is used to esterify carboxylic acids to lower AV.
\end{abstract}

Keywords: estolides; castor oil; lipase; candida antarctica lipase A

\section{Introduction}

Estolides are a class of fatty acid polyesters with interesting biological properties [1]. Further, synthetic estolides have recently received increasing attention. Attractive physical properties, including improved hydrolytic stability compared to glycerides, while being biodegradable and originating from renewable resources, has spurred interest in diverse industrial uses, like as biolubricants [2-4], plasticizers [5], and applications to provide emulsification or a viscosity increase [6].

Estolides can be prepared from hydroxy fatty acids by esterification (Figure 1), or from unsaturated fatty acids by the acid-catalyzed addition to the double bond [7-9]. Harsh conditions can however result in colored products and undesired side reactions that would require extra costs for purification. Enzymatic synthesis of estolides using lipases has therefore been investigated as an alternative to overcome this $[2,3,10-15]$. The enzyme-mediated reactions promise mild reaction conditions such as ambient temperature and pressure and neutral $\mathrm{pH}$. Together with high selectivity this results in very clean reactions. Like the acid-catalyzed routes, control of polymerization degree (chain length) however continues to be a challenge. A chemical alternative with utilization of protecting groups seeks to address this but appears cumbersome and costly in large scale [16].

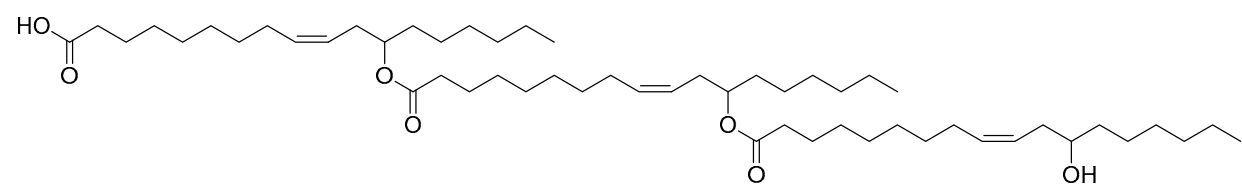

Figure 1. An estolide trimer based on ricinoleic acid. 
Castor oil contains 90\% ricinoleic acid (12-hydroxy-9-cis-octadecenoic acid) and is therefore a natural starting point for estolide synthesis. The reported enzymatic approaches however typically go through hydrolysis of castor oil to produce free ricinoleic acid, or start from commercial ricinoleic acid, which is then condensed to estolides $[2,3,9,10,14,15]$. What we report here is the lipase-catalyzed synthesis of estolides directly from castor oil by transesterification in a green process using only water as solvent and producing only glycerol as byproduct.

\section{Results}

\subsection{Lipase Screening}

\subsubsection{Liquid Enzymes}

Commercial production of estolides from ricinoleic acid would first involve fat splitting of castor oil. As an alternative to this, lipases may be able to catalyze the direct transesterification of castor oil into estolides. To investigate this, a range of Novozymes' lipolytic enzymes were assayed. This included the Candida antarctica lipase A (CALA), the Candida antarctica lipase B (CALB), as well as lipases from Thermomyces lanuginosus (TLL), Rhizomucor miehei (RML), and Geotrichum candidum (GCL), and finally a genetically engineered variant of Humicola insolens cutinase (HIC). To enable a high throughput for screening different conditions, reactions were conducted in parallel in a sealed 24-well round-bottom deep-well plate, with efficient magnetic stirring in all wells using a custom-designed stirrer-hotplate. The lipases were assayed in a system with castor oil-water $(2: 1)$ at $40{ }^{\circ} \mathrm{C}$ for $24 \mathrm{~h}$, after which estolide formation was determined quantitatively by ${ }^{1} \mathrm{H} \mathrm{NMR}$, and hydrolysis was quantified by titration of free carboxylic acids. In Table 1, this is reported as the average estolide number (EN) and the acid value (AV), respectively.

Table 1. Lipase screening.

\begin{tabular}{ccc}
\hline Lipase & EN & AV \\
\hline Blank & 0.0 & 2 \\
CALA & 2.45 & 25 \\
CALB & 0.02 & 25 \\
TLL & 0.05 & 79 \\
RML & 0.09 & 110 \\
GCL & 0.52 & 43 \\
HIC & 0.45 & 88 \\
\hline
\end{tabular}

The EN is the number of ricinoleic acid units added to a base unit. The NMR analysis relied on the esterified ricinoleic acid $\mathrm{CH}-\mathrm{OR}$ signal at $4.8-4.9 \mathrm{ppm}$ and the non-esterified ricinoleic $\mathrm{CH}-\mathrm{OH}$ signal at 3.6-3.7 ppm. The EN was directly found as the ratio of these two integrals. Based on this NMR quantification, CALA clearly resulted in the most significant estolide formation while keeping a relatively low degree of hydrolysis. This demonstrates a significant enzymatic preference for a lipophilic nucleophilic donor, to catalyze the transesterification over hydrolysis, even in a system with abundant water.

Since the NMR analysis only describes average properties, MS-methods were investigated to identify and characterize individual components in the reaction mixtures. LC-MS analyses provided some chromatographic separation on a C18 RP-column, whereas the coupling to ESI-MS with application of $\mathrm{MS}^{2}$ and $\mathrm{MS}^{3}$ methods, allowed isobaric substances to be studied further. Specifically, loss of the oleate radical $\mathrm{m} / \mathrm{z} 280$, from fragmentation of the secondary -CH-OR, was frequently identified. For providing an overview of the species, MALDI MS was however preferred. As expected, such analysis revealed a mixture of estolide oligomers, as well as glycerides and glyceride/estolide hybrids (glycerol-containing estolides). Several isomers have the same molecular mass. In Figure 2, these are shown schematically and grouped in structural classes. Pure estolides are referred to as E\# and 
glycerides are called G\#. The number (\#) denotes the estolide number. MALDI analysis of the CALA reaction identified estolides up to E4 and glycerides up to G6. The other lipases, also showing less estolide formation by NMR, formed only the smaller components (Table 2).
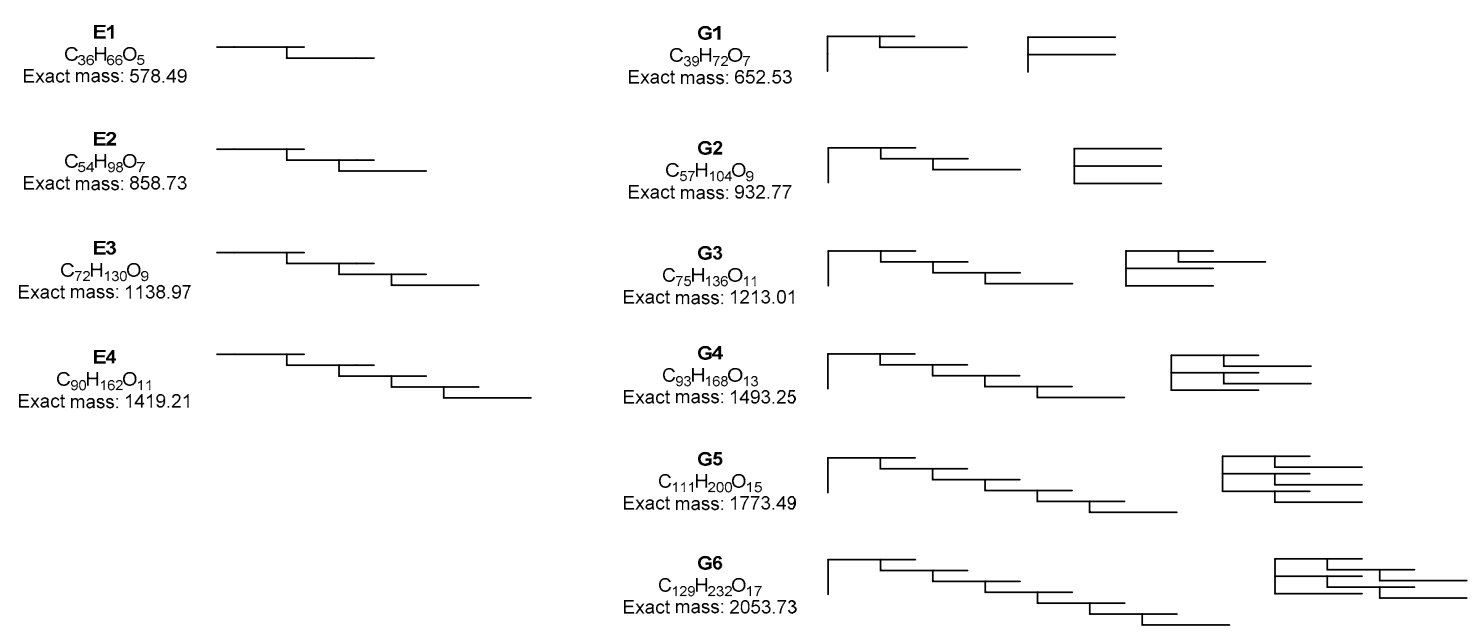

Figure 2. Structures of estolides (E) and glycerides (G). Within each glyceride group (G1-G6) the different isomers have identical chemical formulas and masses (not all isomers are shown).

Table 2. MALDI MS analysis of product mixtures from lipase screening, showing presence (+) and absence (-) of ricinoleic acid (R), estolides (E1-E4), and glycerides (G1-G6).

\begin{tabular}{cccccccccccc}
\hline Lipase & R & E1 & E2 & E3 & E4 & G1 & G2 & G3 & G4 & G5 & G6 \\
\hline CALA & + & + & + & + & + & + & + & + & + & + & + \\
CALB & + & - & - & - & - & - & + & - & - & - & - \\
TLL & + & - & - & - & - & + & + & - & - & - & - \\
RML & + & - & - & - & - & + & + & - & - & - & - \\
GCL & + & + & + & - & - & + & + & + & - & - & - \\
\hline
\end{tabular}

\subsubsection{Immobilized Enzymes}

Since water concentration is expected to play a significant role in the reaction, a few experiments were also conducted with immobilized lipases. These included both the already tested lipases, as well as the Candida rugosa lipase. All were immobilized on polymethacrylate resin beads. Reactions were conducted both in the absence of added water, and with a 2:1 oil-water ratio. Interestingly, none of the enzymes performed as well as seen with the liquid enzymes. Immobilized CALA only provided a modest average $\mathrm{EN}=0.18$. The significant difference between reactions catalyzed by free and immobilized enzymes could be related to transport limitations in the viscous oil and 3-phase system with oil, water, and the porous support material.

\subsection{Optimizing the CALA Reaction}

\subsubsection{Temperature}

Performing the CALA reaction at $25^{\circ} \mathrm{C}, 40{ }^{\circ} \mathrm{C}$, and $65^{\circ} \mathrm{C}$, resulted in EN of 1.38, 2.13, and 2.03 , respectively. MALDI MS characterization showed identical results for the three temperatures, with ricinoleic acid (R), E1-E4, and G1-G5 being identified. Based on this, it was decided to fix the temperature at $40{ }^{\circ} \mathrm{C}$ in the following experiments. 


\subsubsection{Water Content}

To determine optimal water content, volume of the water phase was varied (Figure 3). No added water resulted in fluctuating results, whereas a plateau was obtained around $10-40 \%$ water with EN = 2-2.5. More water resulted in lower conversions. The estolides and glycerides identified with MALDI MS followed the conversion, i.e., up to E4 and G6 were found in the reactions with high EN, whereas only the lower species were found in reactions with lower conversion (MALDI MS data shown in Supplementary Material, Table S1). For subsequent experiments, it was decided to maintain the 33\% water phase (2:1 oil-water ratio).

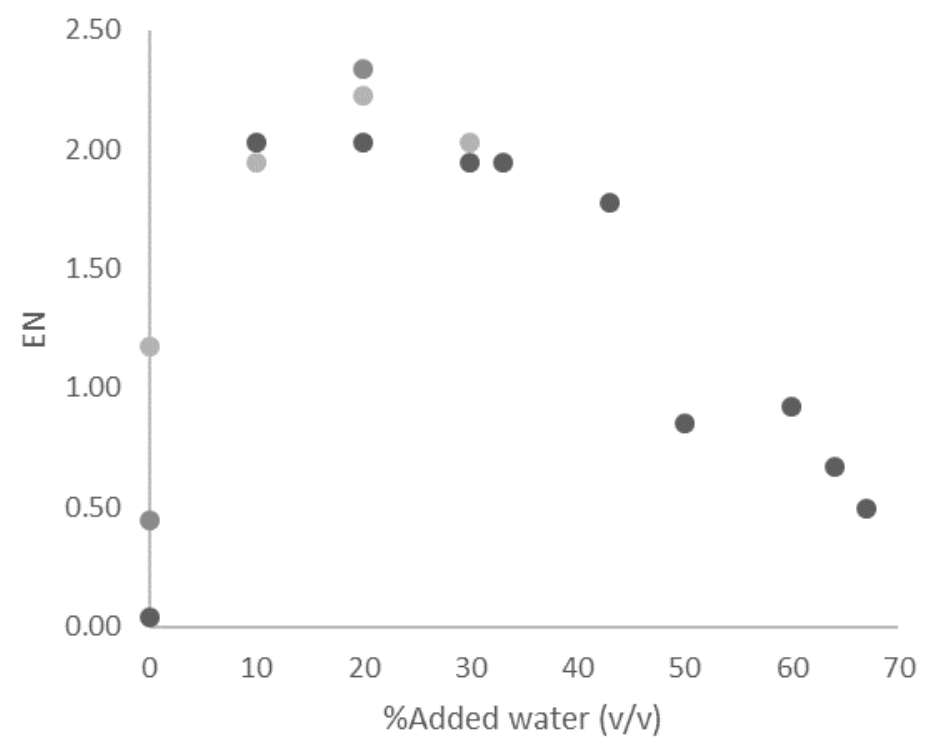

Figure 3. EN measured by NMR as a function of added water to the reaction (\% of total reaction volume). Some reactions were performed in duplicates or triplicates.

\subsubsection{Time Course}

Using $40{ }^{\circ} \mathrm{C}$ and 2:1 oil-water, EN was followed over time. As shown in Figure 4, estolide formation initially increased rapidly, then leveled off, reaching $\mathrm{EN}=2.40$ after $24 \mathrm{~h}$ and $\mathrm{EN}=2.67$ after $48 \mathrm{~h}$. The MALDI MS data further showed that the longer oligomers are only formed slowly. Only in the $24 \mathrm{~h}$ reaction mixture (and later) can E3 and E4 be identified.

\subsection{4. $\mathrm{pH}$-Effect}

Results so far indicate that polymerization stops after E4. It was speculated, that this could be explained by enzyme inactivation resulting from a $\mathrm{pH}$-drop when free fatty acids are released. To examine this, phosphate buffer $\mathrm{pH} 7.0$ was tested as the aqueous phase. Whereas the unbuffered system resulted in a pH-drop to 5, $100 \mathrm{mM}$ phosphate resulted in $\mathrm{pH}$ 6, and $500 \mathrm{mM}$ phosphate maintained $\mathrm{pH}$ 7. However, upholding $\mathrm{pH} 7$ did not result in higher EN, indicating that other factors are limiting further reaction. 


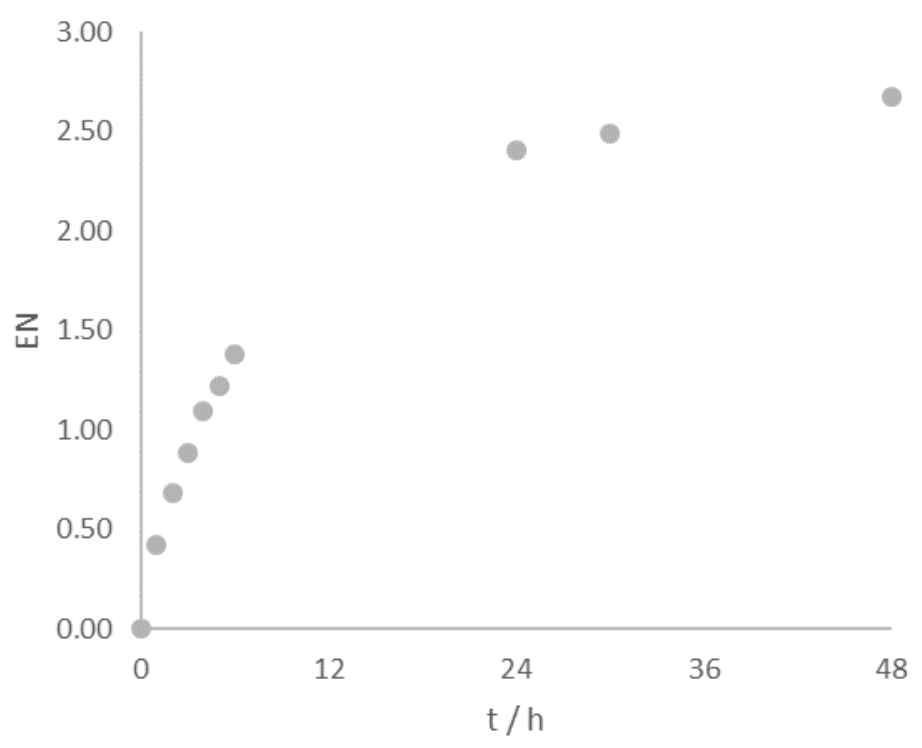

Figure 4. EN measured by NMR as a function of reaction time.

\subsection{Two-Enzyme Process}

\subsubsection{Reaction Sequence}

The MALDI MS results clearly show that a mixture of both estolides and glycerides in different lengths are formed. Removing the glycerol from G1-G6 by selective hydrolysis would convert them to estolides E1-E6, thereby effectively cleaning up the reaction mixture. Classical lipases such as TLL are known for their ability to hydrolyze glycerides. On this background, two-enzyme reactions were evaluated, combining the specificities of CALA and TLL. This involved both reactions with (i) CALA being added first to produce the estolides mixture, followed by glyceride hydrolysis by TLL; and (ii) TLL added first to procedure ricinoleic acid, followed by condensation to estolides by CALA; and (iii) both enzymes added together. In the two former approaches, the water phase was removed after step one, before adding the 2nd enzyme. However, only option (i) the two-step reaction with CALA first, produced good conversion to estolide (Table 3). Remarkably, due to the specificity of TLL toward glycerides, only very little estolide hydrolysis was observed. The MALDI MS analysis confirmed that the TLL treatment in "process (i) step 2" indeed does clean up the reaction mixture by converting glyceride oligomers to estolides (Table 4).

Table 3. EN measured by NMR for two-enzyme processes.

\begin{tabular}{rcc}
\hline & Step 1 & Step 2 \\
\hline (i) CALA, TLL & 2.70 & 2.70 \\
(ii) TLL, CALA & 0.05 & 0.56 \\
(iii) CALA+TLL & 0.61 & - \\
\hline
\end{tabular}

Table 4. MALDI MS analysis of product mixtures from two-enzyme processes.

\begin{tabular}{cccccccccccc}
\hline Process & R & E1 & E2 & E3 & E4 & G1 & G2 & G3 & G4 & G5 & G6 \\
\hline (i) step 1 & + & + & + & + & + & + & + & + & + & + & + \\
(i) step 2 & + & + & + & + & + & - & - & - & - & - & - \\
(ii) step 1 & + & - & - & - & - & + & + & - & - & - & - \\
(ii) step 2 & + & + & + & - & - & + & + & + & - & - & - \\
(iii) & + & + & + & - & - & + & - & - & - & - & - \\
\hline
\end{tabular}




\subsubsection{Scale up}

The two-enzyme process was performed in larger scale to provide material for further studies and to determine the isolated product yield. Hence, reaction setup was round-bottom flasks with magnetic stirring in a thermostat bath. Starting out with $50 \mathrm{~g}$ castor oil, the oil phase was reduced to 43 $\mathrm{g}$ after step 1 and further to $35 \mathrm{~g}$ after step 2. Assuming castor oil (MW $933 \mathrm{~g} / \mathrm{mol}$ ) is all converted to the estolide trimer E2 (MW $859 \mathrm{~g} / \mathrm{mol}$ ), this corresponds to a yield of $76 \%$. The loss seems to be due to inefficient phase separation when water phases are removed, which may be improved with better centrifugation. NMR analysis resulted in $\mathrm{EN}=2.45$ after step 2. The glyceride to estolide conversion was again confirmed by MALDI MS (Figure 5).

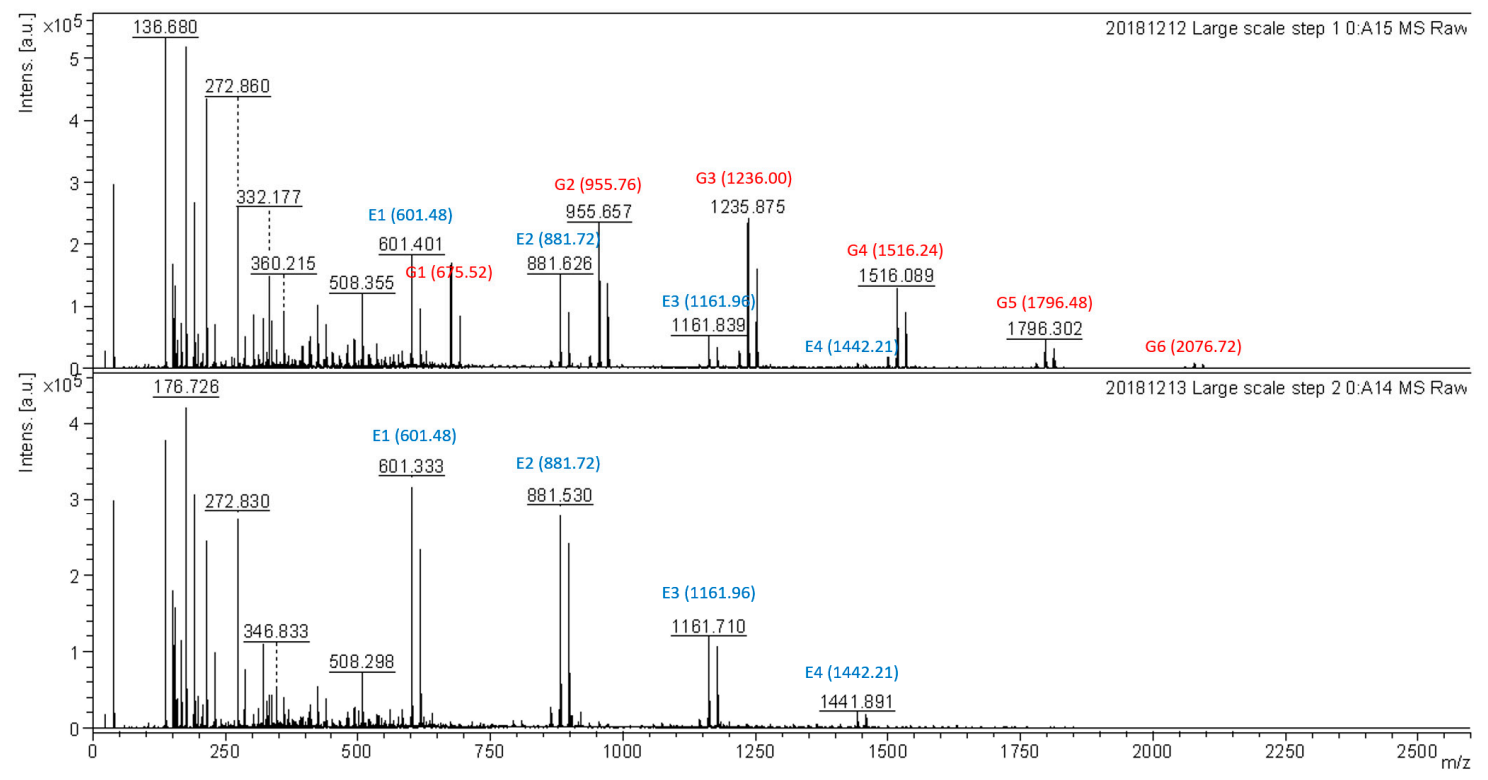

Figure 5. MALDI MS analysis of two-enzyme reaction, step 1 (top) and step 2 (bottom). E1-E4 are marked with blue, while glycerides G1-G6 are marked with red (with theoretical $\mathrm{m} / \mathrm{z}$ for $[\mathrm{M}+\mathrm{Na}]^{+}$).

\subsection{Three-Enzyme Process}

It was speculated that further modification of the reaction mixture from the two-enzyme process, specifically esterification of the free carboxylic acids, could result in attractive low-AV estolides. This is especially important for biolubricants, and other applications involving contact with machinery. Therefore, a three-enzyme process was preliminarily investigated, in which the product from the two-step process was further reacted with 1-hexanol, catalyzed by immobilized CALB (Novozym 435). After removing the immobilized enzyme by filtration and evaporating excess 1-hexanol, the estolide mixture was analyzed by MALDI MS. This clearly showed significant formation of hexyl esters of all estolides (+84 Da, see MALDI MS spectrum S2 in Supplementary Material). NMR showed a triplet signal at $4.05 \mathrm{ppm}$ resulting from the $-\mathrm{CH}_{2} \mathrm{O}$ - of hexyl esters (see NMR spectrum S3 in Supplementary Material). From the NMR integrals it appears that $49 \%$ of the estolide oligomers are hexyl esters. Further reaction can likely be obtained through optimization of conditions, e.g., removing water to drive the equilibrium.

\section{Discussion}

CALA is known for its ability to accommodate bulky secondary alcohols [17]. Here, the lipase further demonstrates a remarkable preference for lipophilic acyl transfer reactions. Hence, despite very high water concentrations, transesterification of castor oil is strongly preferred over hydrolysis. This is unique for CALA relative to the other tested lipases and forms the basis for a one-step synthesis 
of estolides directly from castor oil. Most published lipase-catalyzed routes to estolides start out with producing hydroxy fatty acids in a separate step $[2,3,12]$, or use costly commercially available ricinoleic acid $[10,14,15]$. Condensation to estolides is then typically achieved with Candida rugosa lipase (CRL) in either free or immobilized forms. With the immobilized form, the system can be dried to very low water activity, which is reported to drive the reaction. In such a system, Freire and coworkers reached $\mathrm{EN}=7$, as determined by ${ }^{13} \mathrm{C}$ NMR spectroscopy [2]. The estolide numbers obtained in the present study are lower (approx. 2.5, corresponding to trimers and tetramers on average), but what that means for potential applications is uncertain.

An inherent issue when producing estolides by polymerization reactions is how to control the distribution of products obtained. Producing estolides directly from castor oil is simple and cost-efficient, but also adds new components to the product mixture, namely the glycerides. Interestingly, we found that combining different lipase specificities in multi-stage enzymatic reactions have the potential to modify the products to target specific properties. Hence, glycerol is quantitatively removed by TLL-catalyzed hydrolysis of the glycerides, without affecting the estolides. Further, preliminary results indicate the potential of CALB in esterification of the terminal carboxylic acids to produce low-AV estolides, e.g., for biolubricants applications.

Estolides have been analyzed by gel permeation chromatography [18], HPLC, GC, and a battery of other analytical methods [19]. In the present study, ${ }^{1} \mathrm{H}$ NMR was found to be a fast and quantitative method for providing average EN-numbers directly from the integrals, as well as information about purity and degree of esterification in the 3-enzyme process. It is complemented by an also rapid and simple MALDI MS method, to provide information about individual species in the product mixtures. MS analysis of such a complex blend of isomers is obviously challenged by the fact that several species have the exact same molecular weight (see Figure 2). Preliminary results however demonstrated the potential of $\mathrm{MS}^{\mathrm{n}}$ methods to differentiate between such isobaric substances.

For biotechnological innovation to move from laboratory scale proof-of-concept to industrial production scale, the new process has to offer unique advantages, e.g., properties of the product, or cost-savings compared to established methods. Factors such as safety and sustainability also become increasingly important. In fact, application of lipolytic enzymes for modification of vegetable oils is well-established in the industry. Building on this, the present work has outlined a potential simple and inexpensive procedure for converting castor oil directly into estolides. The process may be conducted at ambient conditions in stirred tank reactors with known commercially available liquid formulated enzyme. Immobilized enzymes, although easy to separate and reuse, are significantly more expensive, often forming a barrier for implementing enzymatic processes. The use of liquid enzyme(s) opens up for a single-use process, although it may also be recycled in the aqueous phase.

\section{Materials and Methods}

\subsection{General Procedures}

All chemicals were purchased from Merck-Sigma-Aldrich (St. Louis, MO, USA), while castor oil was provided by Jayant Agro-Organics Ltd. (Mumbai, India). All enzymes were provided by Novozymes A/S (Bagsvaerd, Denmark). Liquid formulated enzymes included NovoCor AD L (CALA), Lipozyme CALB L (CALB), Lipolase 100 L (TLL), Palatase 20,000 L (RML), Stickaway (HIC), and experimental lipase from Geotrichum candidum (GCL). Immobilized enzymes included Novozym 435 (CALB) as well as the above mentioned liquid enzymes immobilized to a loading of $100 \mathrm{mg} / \mathrm{g}$ by adsorption to Lewatit VP OC 1600 resin beads. Small-scale experiments were performed in parallel in a sealed 24-well round-bottom deep-well plate, using a custom-designed stirrer-hotplate. Mixing was ensured by crosshead magnetic stir bars in each well. Standard conditions were castor oil ( $2 \mathrm{~g})$, water $(1 \mathrm{~mL})$, lipase $\left(0.1 \mathrm{mg}\right.$ enzyme protein, EP, per g of castor oil), $40^{\circ} \mathrm{C}, 500 \mathrm{rpm}$ for $24 \mathrm{~h}$. Prior to analysis, samples were inactivated at $99^{\circ} \mathrm{C}, 600 \mathrm{rpm}$ for $15 \mathrm{~min}$ on an ThermoMixer (Eppendorf, Hamburg, Germany). To separate the oil phase, small scale samples were centrifuged with an MiniSpin 
microcentrifuge (Eppendorf, Hamburg, Germany), whereas large scale samples were centrifuged with Multifuge 3 S-R (Heraeus, Hanau, Germany) large bench centrifuge.

\subsection{Analytical Procedures}

NMR samples were prepared by mixing oil sample $(50 \mu \mathrm{L})$ with chloroform-d $(700 \mu \mathrm{L})$ and analyzed on a Bruker Avance III HD $400 \mathrm{MHz}$ instrument (Bruker Biospin, Fällanden, Switzerland). The EN was calculated from the integrals of the ricinoleic $-\mathrm{CH}-\mathrm{OH}$ signal at $3.65 \mathrm{ppm}$ and the esterified - $\mathrm{CH}$-OR signal at $4.85 \mathrm{ppm}$ as:

$$
\mathrm{EN}=\mathrm{I}_{4.85} / \mathrm{I}_{3.65} \text {. }
$$

In the three-enzyme process, percent of carboxylic acid end-groups esterified with 1-hexanol was calculated from the hexyl ester $-\mathrm{CH}_{2} \mathrm{O}$ - signal at $4.05 \mathrm{ppm}$, assuming there is one carboxylic acid end-group for every one free ricinoleic hydroxyl:

$$
\% \text { hexyl ester }=100 \% \times \mathrm{I}_{4.05} / 2 / \mathrm{I}_{3.65}
$$

MALDI MS analyses were performed on a Bruker UltrafleXtreme MALDI-TOF (Bruker Daltonik, Bremen, Germany) mass spectrometer. Samples were diluted to a final concentration of $1 \mathrm{mg} / \mathrm{mL}$ in $\mathrm{MeCN}_{-} \mathrm{H}_{2} \mathrm{O}$ (1:1) and spotted on the target plate with Super-DHB matrix. A Bruker amaZon SL instrument was used for LC-MS analyses, eluting a C18 RP-column with a gradient of 50\% to $100 \%$ methanol (solvent $\mathrm{B}$ ) vs. $0.1 \mathrm{mM}$ aqueous $\mathrm{NaCl}$ (solvent $\mathrm{A}$ ), and detecting with $\mathrm{ESI}$ MS in positive mode. Titrations were performed by dissolving oil (ca. $0.5 \mathrm{~mL}$, no water phase) in 2-propanol (10 $\mathrm{mL})$. After the addition of $1 \%$ phenolphthalein $(0.5 \mathrm{~mL}), 0.1 \mathrm{M} \mathrm{NaOH}$ was added dropwise until a permanent pink color was observed. For the blank sample, oil $(1 \mathrm{~mL})$ was titrated with $0.025 \mathrm{M} \mathrm{NaOH}$. Acid value (AV) (mg/g) was calculated as:

$$
\mathrm{AV}=\mathrm{c}_{\mathrm{NaOH}} \times \mathrm{V}_{\mathrm{NaOH}} \times \mathrm{M}_{\mathrm{KOH}} / \mathrm{m}_{\text {sample }}
$$

\subsection{Multi-Enzyme Processes}

For the upscaled two-enzyme process, castor oil $(50 \mathrm{~g})$ was mixed with water $(25 \mathrm{~mL})$ and added NovoCor AD L $(0.73 \mathrm{~mL}, 12.5 \mathrm{mg} \mathrm{EP})$. The mixture was incubated in a round-bottom flask under rapid magnetic stirring $(500 \mathrm{rpm})$ at $40^{\circ} \mathrm{C}$ for $24 \mathrm{~h}$. Subsequently, the sample was inactivated at $99{ }^{\circ} \mathrm{C}$ for 15 min and centrifuged for $15 \mathrm{~min}$. The oil phase $(43 \mathrm{~g})$ was then again mixed with water $(21 \mathrm{~mL})$ and added Lipolase $100 \mathrm{~L}$ ( $0.64 \mathrm{~mL}, 10.8 \mathrm{mg}$ enzyme protein). The reaction was stirred for another $24 \mathrm{~h}$ at $40{ }^{\circ} \mathrm{C}$. Inactivation and centrifugation of the second step was performed in a similar matter as step one, resulting in $35 \mathrm{~g}$ estolide mixture. For the three-enzyme process, estolide mixture from the two-step process $(4 \mathrm{~g})$ was mixed with 1-hexanol $(2 \mathrm{~mL})$ and Novozym $435(10 \mathrm{mg})$ in a small round-bottom flask and incubated for $24 \mathrm{~h}$ at $40{ }^{\circ} \mathrm{C}$. The reaction was stopped by enzyme inactivation. No phase separation was observed. Immobilized enzyme was removed by filtration and excess 1-hexanol was removed by rotary evaporation.

Supplementary Materials: The following are available online at http://www.mdpi.com/2073-4344/10/8/835/s1, Figure S1: MS-spectrum of 3-enzyme process, Figure S2: NMR spectrum of 3-enzyme process. Table S1: MALDI MS analysis of product mixtures with different water content.

Author Contributions: Conceptualization, A.R.-M. and J.B.; Data curation, J.B.; Investigation, A.A.; Supervision, A.R.-M. and J.B.; Writing—original draft, A.A.; Writing—review \& editing, J.B. All authors have read and agreed to the published version of the manuscript.

Funding: This research received no external funding.

Acknowledgments: The authors wish to thank Jayant Agro-Organics Ltd. (India) for donating castor oil and Laila Lo Leggio (University of Copenhagen) for fruitful discussions during the project.

Conflicts of Interest: A.R.-M. and J.B. are employed by Novozymes A/S, a leading manufacturer of industrial enzymes, including the ones used in this study. 


\section{References}

1. Kolar, M.J.; Nelson, A.T.; Chang, T.N.; Ertunc, M.E.; Christy, M.P.; Ohlsson, L.; Harrod, M.; Kahn, B.B.; Siegel, D.; Saghatelian, A. Faster protocol for endogenous fatty acid esters of hydroxy fatty acid (FAHFA) measurements. Anal. Chem. 2018, 90, 5358-5365. [CrossRef] [PubMed]

2. Greco-Duarte, J.; Collaco, A.C.A.; Costa, A.M.M.; Silva, L.O.; Da Silva, J.A.C.; Torres, A.G.; Fernandez-Lafuente, R.; Freire, D.M.G. Understanding the degree of estolide enzymatic polymerization and the effects on its lubricant properties. Fuel 2019, 245, 286-293. [CrossRef]

3. Greco-Duarte, J.; Cavalcanti-Oliveira, E.D.; Da Silva, J.A.C.; Fernandez-Lafuente, R.; Freire, D.M.G. Two-step enzymatic production of environmentally friendly biolubricants using castor oil: Enzyme selection and product characterization. Fuel 2017, 202, 196-205. [CrossRef]

4. McNutt, J.; He, Q. Development of biolubricants from vegetable oils via chemical modification. J. Ind. Eng. Chem. 2016, 36, 1-12. [CrossRef]

5. Stolp, L.J.; Joseph, E.; Kodali, D.R. Synthesis and evaluation of soy fatty acid ester estolides as bioplasticizers in poly (vinyl chloride). J. Am. Oil Chem. Soc. 2019, 96, 1291-1302. [CrossRef]

6. Isbell, T.A. Chemistry and physical properties of estolides. Grasas Aceites 2011, 62, 8-20. [CrossRef]

7. Cermak, S.C.; Isbell, T.A. Synthesis of estolides from oleic and saturated fatty acids. J. Am. Oil Chem. Soc. 2001, 78, 557-565. [CrossRef]

8. Isbell, T.A.; Kleiman, R.; Plattner, B.A. Acid-catalyzed condensation of oleic-acid into estolides and polyestolides. J. Am. Oil Chem. Soc. 1994, 71, 169-174. [CrossRef]

9. Wang, G.S.; Sun, S.D. Synthesis of ricinoleic acid estolides by the esterification of ricinoleic acids using functional acid ionic liquids as catalysts. J. Oleo Sci. 2017, 66, ess17031. [CrossRef] [PubMed]

10. Bodalo-Santoyo, A.; Bastida-Rodriguez, J.; Maximo-Martin, M.F.; Montiel-Morte, M.C.; Murcia-Almagro, M.D. Enzymatic biosynthesis of ricinoleic acid estolides. Biochem. Eng. J. 2005, 26, 155-158. [CrossRef]

11. Hayes, D.G.; Kleiman, R. Lipase-catalyzed synthesis and properties of estolides and their esters. J. Am. Oil Chem. Soc. 1995, 72, 1309-1316. [CrossRef]

12. Martin-Arjol, I.; Isbell, T.A.; Manresa, A. Mono-estolide synthesis from trans-8-hydroxy-fatty acids by lipases in solvent-free media and their physical properties. J. Am. Oil Chem. Soc. 2015, 92, 1125-1141. [CrossRef]

13. Todea, A.; Otten, L.G.; Frissen, A.E.; Arends, I.; Peter, F.; Boeriu, C.G. Selectivity of lipases for estolides synthesis. Pure Appl. Chem. 2015, 87, 51-58. [CrossRef]

14. Bodalo, A.; Bastida, J.; Maximo, M.F.; Montiel, M.C.; Gomez, A.; Murcia, M.D. Production of ricinoleic acid estolide with free and immobilized lipase from Candida rugosa. Biochem. Eng. J. 2008, 39, 450-456. [CrossRef]

15. Bodalo, A.; Bastida, J.; Maximo, M.F.; Montiel, M.C.; Murcia, M.D.; Ortega, S. Influence of the operating conditions on lipase-catalysed synthesis of ricinoleic acid estolides in solvent-free systems. Biochem. Eng. J. 2009, 44, 214-219. [CrossRef]

16. Zerkowski, J.A.; Nunez, A.; Solaiman, D.K.Y. Structured estolides: Control of length and sequence. J. Am. Oil Chem. Soc. 2008, 85, 277-284. [CrossRef]

17. Naik, S.; Basu, A.; Saikia, R.; Madan, B.; Paul, P.; Chaterjee, R.; Brask, J.; Svendsen, A. Lipases for use in industrial biocatalysis: Specificity of selected structural groups of lipases. J. Mol. Catal. B Enzym. 2010, 65, 18-23. [CrossRef]

18. Bantchev, G.B.; Cermak, S.C.; Durham, A.L.; Price, N.P.J. Estolide molecular weight distribution via gel permeation chromatography. J. Am. Oil Chem. Soc. 2019, 96, 365-380. [CrossRef]

19. Isbell, T.A.; Kleiman, R. Characterization of estolides produced from the acid-catalyzed condensation of oleic-acid. J. Am. Oil Chem. Soc. 1994, 71, 379-383. [CrossRef]

(C) 2020 by the authors. Licensee MDPI, Basel, Switzerland. This article is an open access article distributed under the terms and conditions of the Creative Commons Attribution (CC BY) license (http://creativecommons.org/licenses/by/4.0/). 